\title{
Degradabilidade da Matéria Seca e Fibra em Detergente Neutro da Cana-de-açúcar (Saccharum spp) com Diferentes Fontes de Proteína
}

\author{
Carolina de Almeida Carmo ${ }^{1}$, Telma Teresinha Berchielli ${ }^{2}$, Pedro de Andrade ${ }^{3}$, \\ Nivea Maria Brancacci Lopes Zeola ${ }^{1}$
}

\begin{abstract}
RESUMO - Foram utilizados cinco bovinos fistulados no rúmen para se determinar a degradação da cana-de-açúcar em dietas com diferentes fontes de proteína degradável, por meio do método de incubação de sacos de náilon. Os tratamentos estudados foram: cana e uréia; cana e farelo de soja; cana, farelo de soja e uréia; cana e glúten de milho; cana, glúten de milho e uréia. Após um período de adaptação de 14 dias, iniciou-se a incubação dos sacos de náilon, nos tempos de 3, 6, 12, 24, 48, 72, 96 e 120 horas. Após o período de incubação, foram determinados o pH e a concentração de amônia no fluido ruminal, em amostras retiradas $0,3,6,9,12,15,18$ e 21 horas após a alimentação. O delineamento estatístico utilizado foi o de blocos casualizados, com tratamentos como parcelas e tempos como subparcelas. A concentração de amônia foi mais elevada nos tratamentos com maior quantidade de proteína degradável, porém não houve efeito significativo para os tratamentos. Para os valores de pH, houve significância, apresentando valores mais elevados para os tratamentos com maior quantidade de proteína degradável. Não se observou efeito significativo das diferentes fontes de nitrogênio sobre a degradação da matéria seca e da fibra em detergente neutro da cana-de-açúcar, sendo que a degradabilidade dessas duas frações variou apenas com o tempo de incubação. Os resultados do experimento não comprovaram o princípio de que a maior quantidade de proteína degradável no rúmen possa induzir maior degradação da FDN da dieta.
\end{abstract}

Palavras-chave: amônia, bovino, $\mathrm{pH}$

\section{Degradability of Dry Matter and Neutral Detergent Fiber of Sugar Cane (Saccharum spp) with Different Protein Sources}

\begin{abstract}
Five rumen fistulated steers were used to study sugar cane degradation with several protein sources through in situ method. The treatments were sugar cane and urea; sugar cane and soybean meal; sugar cane, soybean meal and urea; sugar cane and corn gluten meal; sugar cane, corn gluten meal and urea; and at 3, 6, 12, 24, 48, 72, 96 and 120 hours of incubation. After the incubation period, ammonia concentration and $\mathrm{pH}$ were determined in the ruminal fluid, sampled at times of $0,3,6,9,12,15,18$ and 21 hours after feeding. Randomized blocks, with protein sources and times in split-plot scheme, was used. The ammonia concentration was higher in treatments with high quantity of degradable protein. However, it was observed no variation for treatments. pH data showed significant effect with higher values for treatments with higher quantity of degradable protein. No significant differences was observed were observed for treatments, just for time on residuals of dry matter and neutral detergent fiber, contradicting the theory of ration formulation systems to attend the degradable protein allowances to maximize fiber degradation.
\end{abstract}

Key Words: ammonia, cattle, $\mathrm{pH}$

\section{Introdução}

Os sistemas de formulação de rações mais recentes (AGRICULTURAL FOOD AND RESEARCH COUNCIL - AFRC, 1993; NATIONAL RESEARCH COUNCIL - NRC, 1996), apresentam as taxas de degradação ruminal de nutrientes e síntese de proteína microbiana que, juntamente com a digestão pós ruminal, permitem estimar o fluxo de nutrientes para o animal.

Esses sistemas procuram ajustar a disponibilidade de energia do substrato para os microorganismos com suas demandas de nitrogênio (amônia e ou aminoácidos). Entretanto, dúvidas ocorrem quanto à necessidade de nitrogênio para obtenção máxima da degradação da fibra e do crescimento microbiano.

No Brasil, os volumosos compõem a maior parte da dieta dos ruminantes, e a degradação ruminal destes alimentos depende da eficiência dos microorganismos presentes no rúmen. Dessa forma, torna-se imprescindível determinar o suprimento de nitrogênio para os microorganismos maximizarem a degradação da fibra.

A cana-de-açúcar, como opção de volumoso, apresenta grande quantidade de carboidratos solú-

\footnotetext{
${ }_{1}^{1}$ Bolsistas PIBIC/CNPq. E.mail: cacarmo@esalq.usp.br; nivea@fcav.unesp.br

2 Professor da FCAV-UNESP-Jaboticabal, Pesquisador do CNPq. E.mail: ttberchi@fcav.unesp.br

3 Professor da FCAV-UNESP-Jaboticabal.
} 
veis, que são rapidamente fermentados no rúmen. Porém, a fibra que também constitui porção considerável, apresenta baixa degradação ruminal que freqüentemente é atribuída ao baixo teor de proteína do alimento. Para se corrigir essa deficiência é recomendado, o uso de elevadas quantidades de uréia.

Alguns dados de desempenho com dietas à base de cana-de-açúcar foram revistos por BOIN e TEDESCHI (1993), mostrando que a alimentação de bovinos à base de cana-de-açúcar, suplementada com nitrogênio não protéico e minerais, proporcionou nutrientes um pouco acima das exigências de manutenção, sendo necessário o uso de suplementos adicionais para obter maiores ganhos de peso.

O valor nutritivo da cana-de-açúcar é limitado pela baixa taxa de digestão da parede celular, que contribui com pouca energia metabolizável para o animal e também reduz a eficiência de utilização dos açúcares solúveis através do efeito negativo sobre o ecossistema ruminal, devido à baixa taxa de turnover no rúmen ( PRESTON, 1984).

Outras limitações importantes da cana-de-açúcar, discutidas por LIMA e MATTOS (1993), seriam o baixo suprimento de aminoácidos e glicose pós rúmen, limitando o consumo de MS, a baixa porcentagem de nitrogênio na MS, além do baixo teor de fósforo.

Vários fatores afetam a degradação da fração fibrosa dos volumosos utilizados na alimentação dos ruminantes. Fatores químicos são discutidos por HOOVER (1986), relatando que o decréscimo no $\mathrm{pH}$ ruminal parece ser o principal impacto para redução na degradação da fibra. Uma depressão no $\mathrm{pH}$ ruminal para aproximadamente 6,0 causa uma pequena redução na digestão da fibra, entretanto quando o pH cai para 5,5 ou 5,0 o crescimento dos microorganismos celulolíticos e a digestão da fibra podem ser completamente inibidos.

LUDOVICO e MATTOS (1994) observaram que em dietas à base de cana-de-açúcar suplementadas com diferentes níveis de semente de algodão, o pH no fluido ruminal variou de 7,02 a 7,50. PEREIRA et al. (1996) obtiveram valores médios de $\mathrm{pH}$ de 7,44 para a dieta constituída de cana mais uréia, e 6,48 para cana mais uréia e concentrado.

Segundo AROEIRA et al. (1993b), em novilhos alimentados com cana-de-açúcar e uréia, suplementados com farelo de arroz ou de algodão, os valores de $\mathrm{pH}$ ruminal não diferiram entre os tratamentos, foram observados valores médios de 6,50.
A concentração de amônia no rúmen pode influenciar na degradação da fibra. BELASCO (1954) observou que a máxima digestão da celulose ocorreu quando a concentração de amônia foi de aproximadamente $430 \mathrm{mg} / \mathrm{L}$ de conteúdo ruminal.

SLYTER et al. (1979), avaliando o efeito da concentração de amônia no rúmen, concluíram que de 20 a $50 \mathrm{mg}$ de $\mathrm{NH}_{3}$ por litro de fluido ruminal promovia-se o máximo crescimento dos microorganismos ruminais. Valor semelhante de $30 \mathrm{mg} \mathrm{NH} / \mathrm{L}$, foi encontrado por de FARIA e HUBER (1984). Entretanto os autores consideraram esta concentração baixa para a ótima fermentação ruminal, pois de acordo com Mehrez et al. (1977), citados por de FARIA e HUBER (1984), a máxima atividade fermentativa no rúmen é obtida quando a concentração de amônia está entre 190 e 230 mg/L.

Mudanças no ambiente ruminal podem ocasionar grande variação na concentração de amônia; este fato talvez tenha influência sobre a proporção com que a amônia será absorvida pelos microorganismos, afetando assim a produção microbiana (Smith, 1979, citado por HOOVER, 1986).

AROEIRA et al. (1993b) encontraram concentrações médias de amônia no fluido ruminal de bovinos alimentados com cana-de-açúcar, suplementados com farelo de algodão de $236 \mathrm{mg} / \mathrm{L}$, enquanto os suplementados com farelo de arroz apresentaram concentrações de $166 \mathrm{mg} / \mathrm{L}$.

LUDOVICO e MATTOS (1994), estudando os parâmetros ruminais em bovinos alimentados com cana-de-açúcar suplementados com diferentes níveis de semente de algodão, obtiveram concentrações médias de amônia ruminal variando de 69 a $111,9 \mathrm{mg} / \mathrm{L}$.

Em dietas de cana-de-açúcar, PEREIRA et al. (1996) encontraram concentrações médias de amônia de $95 \mathrm{mg} / \mathrm{L}$ para cana-de-açúcar mais uréia e de $115 \mathrm{mg} / \mathrm{L}$ de conteúdo de amônia ruminal para cana e uréia mais concentrado.

São poucos os trabalhos publicados sobre a degradação ruminal da fibra da cana-de-açúcar, sendo mais freqüentes dados de digestibilidade.

Valdez et al. (1977), citados por LIMA e MATTOS (1993), demonstraram que a degradabilidade da fração fibrosa da cana-de-açúcar era de apenas $19,5 \%$, contrastando com os altos valores de digestibilidade da MS.

ALCÂNTARA et al. (1989), ao estudarem o efeito da ensilagem da cana-de-açúcar com $\mathrm{NaOH}$, 
da cana-de-açúcar fornecida fresca e a silagem não tratada, em experimento com ovinos, observaram que o desaparecimento in situ da MS, após 24 horas de incubação no rúmen, foi de 55,6; 62,7; e 50,2\%, respectivamente, para silagem de cana-de-açúcar tratada com $\mathrm{NaOH}$, cana-de-açúcar fresca e a silagem de cana-de-açúcar não tratada.

Avaliando a degradabilidade in situ da MS e PB de vários alimentos em vacas em lactação, VALADARES FILHO et al. (1990) observaram taxa de degradação de $0,2 \% / \mathrm{h}$ para a MS da cana-deaçúcar, mas alertaram que este valor poderia estar subestimado, devido à redução na digestão de volumosos, induzida pelo elevado teor de concentrados na ração basal (45\%) que poderia afetar o $\mathrm{pH}$ e a atividade dos microorganismos ruminais.

AROEIRA et al. (1993a), trabalhando com canade-açúcar mais uréia suplementada com farelo de algodão e farelo de arroz, encontraram taxa de degradação da MS da cana-de-açúcar de 3,2\%/h, sendo que grande parte do material foi rapidamente solubilizada $(55,2 \%)$, fração esta correspondente ao conteúdo celular. A parede celular foi muito pouco degradada, no rúmen, ao longo das 72 horas de degradação $(43,7 \%)$.

Avaliando a degradabilidade dos nutrientes da cana-de-açúcar e do farelo de algodão em bovinos alimentados com farelo de algodão e cana-de-açúcar adicionada de três níveis de uréia, AROEIRA et al. (1993c) não observaram diferença na degradação da MS e FDN com o aumento do nível de uréia na dieta.
Em bovinos alimentados com cana-de-açúcar sob diferentes formas, a taxa de degradação para MS da cana-de-açúcar integral e uréia foi de $6,0 \% / \mathrm{h}$, conforme (PEREIRA et al., 1996).

UGARTE et al. (1994), substituindo a uréia por um alimento protéico a base de melaço, em dietas a base de cana-de-açúcar, observaram 43,3\% de degradação da fração fibrosa após 72 horas de incubação.

As diferenças existentes entre os dados de degradação da fibra da cana-de-açúcar, devem-se, provavelmente, às formas de ajuste dos dados ao modelo matemático utilizado para avaliação dos resultados, variações nos alimentos e materiais utilizados.

O objetivo do presente trabalho foi avaliar a influência de diferentes fontes protéicas na degradação da fibra da cana-de-açúcar.

\section{Material e Métodos}

No experimento foram utilizados cinco bovinos, machos, com idade aproximada de quatro anos, castrados com peso médio de $470 \mathrm{~kg}$ e providos de cânula ruminal permanente. Os animais permaneceram durante o período experimental em baias individuais semi cobertas, de 7 × 2,8 m, com cocho individual, bebedouros comuns a cada duas baias, piso cimentado.

Os alimentos utilizados foram cana-de-açúcar fresca picada, farelo de soja, glúten de milho e uréia, cujas composições bromatológicas constam na Tabela 1.

Cada dieta constituía um tratamento, e o princípio da formulação foi o de atendimento do potencial de

Tabela 1 - Teores de matéria seca (MS), proteína bruta (PB), extrato etéreo (EE), extrativo não nitrogenado (ENN), matéria mineral (MM), fibra em detergente neutro (FDN) e energia bruta (EB) dos alimentos

Table 1 - Dry matter (DM), crude protein (CP), ether extract (EE), nitrogen free extracts (NFE), ash, neutral detergent fiber (NDF) and gross energy (GE) contents of food

\begin{tabular}{lccccccc}
\hline Alimento & \multicolumn{9}{c}{$\begin{array}{c}\text { Nutrientes (\% MS) } \\
\text { Food }\end{array}$} & \multicolumn{9}{c}{ Nutrient (DM\%) } & $\begin{array}{c}\text { EB(Mcal/kg de MS) } \\
\text { GE (Mcal/kg DM) }\end{array}$ \\
\cline { 2 - 7 } & MS (\%) & PB & EE & ENN & MM & FDN & \\
\hline $\begin{array}{l}\text { Cana-de-açúcar } \\
\text { Sugar cane }\end{array}$ & 28,20 & 2,38 & 0,41 & 56,22 & 2,28 & 69,94 & 4,93 \\
$\begin{array}{l}\text { Farelo de soja } \\
\text { Soybean meal }\end{array}$ & 87,53 & 59,35 & 0,73 & 26,98 & 7,10 & 15,00 & 5,10 \\
$\begin{array}{l}\text { Glúten de milho } \\
\text { Corn gluten meal }\end{array}$ & 90,32 & 66,79 & 0,42 & 29,20 & 1,37 & 4,12 & 5,93 \\
$\begin{array}{l}\text { Uréia } \\
\text { Urea }\end{array}$ & 98,00 & 275,00 & - & - & - & - & - \\
\hline
\end{tabular}

Obs: Valores de MS e PB da uréia e FDN do farelo de soja são provenientes de tabela.

Obs: Urea DM and CP values, and soybean meal NDF values are from table.

Rev. bras. zootec., 30(6S):2126-2133, 2001 
crescimento microbiano para os tratamentos canade-açúcar e uréia (UR), cana-de-açúcar e farelo de soja (FS) e cana-de-açúcar, farelo de soja e uréia (FU), segundo AFRC (1993). Os tratamentos que continham uréia foram formulados seguindo o critério de atendimento de $30 \%$ do potencial microbiano com uréia, e os tratamentos cana-de-açúcar e glúten (GL), e cana-de-açúcar, glúten e uréia (GU) foram formulados tendo as mesmas quantidades de PB de (FS) e (FU), respectivamente. Nas Tabelas 2 e 3 são apresentadas as quantidades de alimentos e a composição bromatológica das dietas.

Os animais foram alimentados uma vez ao dia, no período da manhã, sendo a cana-de-açúcar oferecida no cocho, juntamente com $70 \mathrm{~g} /$ animal de sal mineral, os demais alimentos foram colocados diretamente no rúmen através da cânula.

No tratamento uréia, a quantidade de uréia foi dividida em duas partes, sendo uma colocada no rúmen no período da manhã e outra no período da tarde.

Para a incubação, a cana-de-açúcar fresca, picada, foi seca em estufa a $65^{\circ} \mathrm{C}$ por 48 horas, e passada em moinho a martelo, dotado de peneira com crivos de $1 \mathrm{~cm}$, para então, ser colocada nos sacos de náilon.

Os sacos para incubação no rúmen foram confeccionados em tecido de náilon, com poros de aproximadamente $50 \mathrm{~mm}$ de diâmetro, nas medidas de $7 \times 14 \mathrm{~cm}$, selados por fusão com resistência elétrica. Foram identificados, pesados e receberam aproximadamente $5 \mathrm{~g}$ de MS dos alimentos.

Tabela 2 - Quantidade de alimento nas dietas

Table 2 - Food content in the diets

\begin{tabular}{|c|c|c|c|c|}
\hline \multirow[t]{2}{*}{$\begin{array}{l}\text { Dietas } \\
\text { Diets }\end{array}$} & \multicolumn{4}{|c|}{$\begin{array}{l}\text { Alimento }(\mathrm{kg}) \\
\text { Food }(\mathrm{kg})\end{array}$} \\
\hline & $\begin{array}{l}\text { Cana-de-açúcar } \\
\text { Sugar cane }\end{array}$ & $\begin{array}{l}\text { Uréia } \\
\text { Urea }\end{array}$ & $\begin{array}{l}\text { Farelo de soja } \\
\text { Soybean meal }\end{array}$ & $\begin{array}{l}\text { Glúten de milho } \\
\text { Corn gluten meal }\end{array}$ \\
\hline $\begin{array}{l}\text { Uréia } \\
\text { Urea }\end{array}$ & 22,5 & 0,170 & - & - \\
\hline $\begin{array}{l}\text { Farelo de soja } \\
\text { Soybean meal }\end{array}$ & 22,5 & - & 1,630 & - \\
\hline $\begin{array}{l}\text { Farelo de soja + uréia } \\
\text { Soybean meal + urea }\end{array}$ & 22,5 & 0,075 & 0,890 & - \\
\hline $\begin{array}{l}\text { Glúten } \\
\text { Corn gluten meal }\end{array}$ & 22,5 & - & - & 1,240 \\
\hline $\begin{array}{l}\text { Glúten + uréia } \\
\text { Corn gluten meal }+ \text { urea }\end{array}$ & 22,5 & 0,075 & - & 0,670 \\
\hline
\end{tabular}

Tabela 3 - Teores de matéria seca (MS), proteína bruta $(\mathrm{PB})$, extrato etéreo (EE), extrativo não nitrogenado (ENN), matéria mineral (MM), fibra em detergente neutro (FDN) e energia bruta (EB) das dietas

Table 3 - Dry matter (DM), crude protein (CP), ether extract (EE), nitrogen free extracts (NFE), ash, neutral detergent fiber (NDF) and gross energy (GE) contents of diet

\begin{tabular}{|c|c|c|c|c|c|c|c|}
\hline \multirow[t]{2}{*}{$\begin{array}{l}\text { Dietas } \\
\text { Diets }\end{array}$} & \multicolumn{6}{|c|}{$\begin{array}{c}\text { Nutrientes }(\% \mathrm{MS}) \\
\text { Nutrients }(D M \%)\end{array}$} & \multirow[t]{2}{*}{$\begin{array}{c}\mathrm{EB}(\mathrm{Mcal} / \mathrm{kg} \text { de MS) } \\
G E(M c a l / k g D M)\end{array}$} \\
\hline & $\begin{array}{l}\text { MS } \\
D M\end{array}$ & $\begin{array}{l}\mathrm{PB} \\
C P\end{array}$ & $\begin{array}{l}\mathrm{EE} \\
E E\end{array}$ & $\begin{array}{l}\mathrm{ENN} \\
N F E\end{array}$ & $\begin{array}{l}\mathrm{MM} \\
\text { Ash }\end{array}$ & $\begin{array}{l}\text { FDN } \\
N D F\end{array}$ & \\
\hline $\begin{array}{l}\text { Uréia } \\
\text { Urea }\end{array}$ & 30,02 & 9,50 & 0,40 & 2,22 & 54,75 & 68,11 & 4,80 \\
\hline $\begin{array}{l}\text { Farelo de soja } \\
\text { Soybean meal }\end{array}$ & 39,11 & 12,85 & 0,46 & 3,16 & 50,85 & 59,85 & 4,96 \\
\hline $\begin{array}{l}\text { Farelo de soja + uréia } \\
\text { Soybean meal + urea }\end{array}$ & 35,34 & 11,23 & 0,44 & 2,78 & 52,50 & 63,30 & 4,90 \\
\hline $\begin{array}{l}\text { Glúten } \\
\text { Corn gluten meal }\end{array}$ & 37,51 & 12,03 & 0,41 & 2,15 & 52,17 & 60,08 & 5,08 \\
\hline $\begin{array}{l}\text { Glúten + uréia } \\
\text { Corn gluten meal + urea }\end{array}$ & 34,28 & 10,67 & 0,41 & 2,18 & 53,31 & 63,54 & 4,96 \\
\hline
\end{tabular}

Rev. bras. zootec., 30(6S):2126-2133, 2001 
A fração solúvel dos alimentos contidos nos sacos de náilon, foi determinada mantendo os sacos em água a $38^{\circ} \mathrm{C}$ por uma hora, depois de lavados e secos, foram pesados, sendo a diferença entre os pesos inicial e final considerada como a fração solúvel.

Após um período de adaptação de 14 dias, iniciou-se a incubação dos sacos de náilon, que eram previamente embebidos em água por uma hora, presos às correntes que permaneciam no interior do rúmen, colocados de acordo com os tempos de incubação 3 , $6,12,24,48,72,96$ e 120 horas, obedecendo sempre o mesmo horário de entrada.

Quando retirados, os sacos eram lavados em água corrente, e secos em estufa de ventilação forçada a $65^{\circ} \mathrm{C}$ por 48 horas; novamente pesados e tendo seus conteúdos transferidos para embalagens de plástico, para análises posteriores de FDN, segundo SILVA (1990).

As coletas de líquido ruminal foram feitas após o período de incubação dos saquinhos, em intervalos de 6 horas por 2 dias, alternando os horários, para que se tivessem dados em intervalos de 3 horas, ao longo de um dia. O conteúdo ruminal coletado através da cânula dos animais era colocado em um tecido de algodão e torcido, obtendo-se apenas o líquido, dividido em duas amostras; uma para leitura de $\mathrm{pH}$, feita logo após a coleta, e a segunda para posterior quantificação de nitrogênio amoniacal, conforme metodologia citada por PRESTON (1986).

O delineamento estatístico utilizado foi o de blocos casualizados, com tratamentos como parcelas e tempos como subparcelas.

\section{Resultados e Discussão}

Na Tabela 4 são apresentados os dados de resíduos de degradação da MS (RDMS) e FDN (RDFDN) da cana-de-açúcar após 72 horas de incubação, valores médios de $\mathrm{pH}$ e concentração de amônia no fluido ruminal. Não houve diferença significativa para os tratamentos principais (dietas), apenas para os tempos de amostragem, mostrando que a degradabilidade da proteína não influenciou na de-

Tabela 4 - Resíduos de degradação da MS (MS) e FDN (FDN) da cana-de-açúcar, valores médios de pH e concentração de amônia $\left(\mathrm{NH}_{3} \mathrm{mg} / \mathrm{L}\right)$ no fluido ruminal

Table 4 - Degradation residuals of DM (DM) and NDF (NDF) of sugar cane, $\mathrm{pH}$ and ammonia concentration ( $\left.\mathrm{NH}_{3} \mathrm{mg} / \mathrm{L}\right)$ in the ruminal fluid

\begin{tabular}{|c|c|c|c|c|}
\hline $\begin{array}{l}\text { Dietas } \\
\text { Diet } \\
\end{array}$ & $\begin{array}{l}\operatorname{MS}(\%) \\
D M(\%)\end{array}$ & $\begin{array}{l}\mathrm{FDN}(\%) \\
N D F(\%)\end{array}$ & $\begin{array}{l}\mathrm{NH}_{3}(\mathrm{mg} / \mathrm{L}) \\
\mathrm{NH}_{3}(m g / L)\end{array}$ & $\begin{array}{l}\mathrm{pH} \text { (média) } \\
\text { pH (average) }\end{array}$ \\
\hline Uréia & 47,12 & 84,65 & 710,41 & $6,87^{\mathrm{a}}$ \\
\hline Urea & & & & \\
\hline $\begin{array}{l}\text { Farelo de soja } \\
\text { Soybean meal }\end{array}$ & 45,71 & 82,31 & 140,37 & $6,12^{b}$ \\
\hline $\begin{array}{l}\text { Farelo de soja + uréia } \\
\text { Soybean meal }+ \text { urea }\end{array}$ & 44,86 & 77,91 & 215,69 & $6,42^{\mathrm{ab}}$ \\
\hline Glúten & 46,87 & 84,05 & 168,13 & $5,96^{\mathrm{b}}$ \\
\hline $\begin{array}{l}\text { Corn gluten meal } \\
\text { Glúten + uréia } \\
\text { Corn gluten meal+ urea }\end{array}$ & 46,41 & 83,12 & 354,61 & $6,27^{\mathrm{ab}}$ \\
\hline $\begin{array}{l}\text { CV }(\%) \\
\text { Tempos }(\mathrm{h}) \\
\text { Time }(h)\end{array}$ & 8,98 & 12,09 & 258,43 & 12,91 \\
\hline 1 & $55,16^{\mathrm{a}}$ & $97,46^{\mathrm{a}}$ & $148,74^{\mathrm{ab}}$ & $6,64^{\mathrm{a}}$ \\
\hline 2 & $54,85^{\mathrm{a}}$ & $98,82^{\mathrm{a}}$ & $610,09^{a}$ & $6,47^{\mathrm{ab}}$ \\
\hline 3 & $53,82^{\mathrm{a}}$ & $97,35^{\mathrm{a}}$ & $479,61^{\mathrm{ab}}$ & $6,24^{\mathrm{b}}$ \\
\hline 4 & $47,99^{b}$ & $86,78^{b}$ & $333,41^{\mathrm{ab}}$ & $6,15^{b}$ \\
\hline 5 & $43,90^{\mathrm{c}}$ & $79,38^{\mathrm{b}}$ & $566,31^{\mathrm{ab}}$ & $6,13^{b}$ \\
\hline 6 & $39,79^{d}$ & $70,77^{\mathrm{c}}$ & $168,72^{\mathrm{ab}}$ & $6,22^{b}$ \\
\hline 7 & $37,74^{\mathrm{d}}$ & $64,04^{\mathrm{c}}$ & $132,80^{\mathrm{b}}$ & $6,27^{\mathrm{ab}}$ \\
\hline 8 & $36,33^{d}$ & $64,63^{c}$ & $103,06^{\mathrm{b}}$ & $6,49^{\mathrm{ab}}$ \\
\hline CV (\%) & 8,50 & 10,14 & 153,28 & 6,34 \\
\hline
\end{tabular}

Tempos para MS(\%) e FDN(\%): 1, 2, 3, 4, 5, 6, 7 e 8 correspondem a 3, 6, 12, 24, 48, 72, 96 e 120 horas de incubação. Tempos para $\mathrm{NH}_{3}$ (mg/L) e pH: 1, 2, 3, 4, 5, 6, 7 e 8 correspondem a 0, 3, 6, 9, 12, 15, 18 e 21 horas após a alimentação.

Nas colunas, letras iguais correspondem a médias que não diferem pelo teste Tukey $(P>0,05)$.

Time for $D M(\%)$ and $N D F(\%): 1,2,3,4,5,6,7$ and 8 to reply 3, 6, 12, 24, 48, 72, 96 and 120 hours of incubation.

Time for $\mathrm{NH}_{3}(\mathrm{mg} / \mathrm{L})$ e $\mathrm{pH}: 1,2,3,4,5,6,7$ and 8 to reply $0,3,6,9,12,15,18$ and 21 hours after feeding.

In column, same letters to reply means do not differ by Tukey test. (P>.05). 
gradação da MS e FDN; ou que a técnica dos sacos de náilon não é adequada para este tipo de avaliação.

Estes resultados são semelhantes aos obtidos por FRANCO (1997), que sugere ser desnecessário o atendimento da necessidade dos microorganismos em proteína para maximização da degradação da parede celular, contrariando o princípio dos sistemas de formulação de rações (AFRC,1993; NRC, 1996). Esta conclusão deve-se ao fato de que os tratamentos UR, FS e FU foram ajustados para atender o potencial microbiano em proteína degradável, porém os tratamentos GL e GU foram ajustados abaixo deste potencial. De acordo com os sistemas, os tratamentos UR, FS e FU deveriam ter apresentado valores de resíduo de degradação significativamente menores que os tratamentos GL e GU, porém não houve diferença significativa entre os tratamentos.

Os dados de degradação da fibra da cana-deaçúcar encontrados na literatura são extremamente variáveis. Valdez et al. (1977), citados por LIMA e MATTOS (1993), encontraram 19,5\% de degradabilidade, enquanto AROEIRA et al. (1993a) relataram $43,7 \%$ de degradação da parede celular, valor semelhante ao obtido por UGARTE et al. (1994), de 43,3\%, ambos após 72 horas de incubação. AROEIRA et al. (1993c) observaram elevada fração de FDN indigestível, que variou de 53,8 a 55,0\%. No presente trabalho foi determinado $29,23 \%$ de degradação da FDN com 72 horas de incubação. Também, não foi encontrado nenhum trabalho cujo enfoque fosse a influência da degradabilidade da proteína na degradação da fibra da cana-de-açúcar.

Para o cálculo das taxas de degradação e tempo para colonização ("lag time"), a seleção dos tempos de início de degradação e de degradação potencial influenciou os resultados, ou seja, quando a taxa de degradação e o tempo para colonização são calculados excluindo-se alguns tempos de incubação poderão ocorrer modificações nos valores para estas taxas calculadas. Este fato pode ser observado nas Tabelas 5 e 6.

Provavelmente os valores mais corretos, seriam os de início de degradação entre 6 e 12 horas e degradação potencial às 72 horas, pois os tempos 3 e 6 não diferiram entre si, assim como 120, 96 e 72 horas. Assim, excluindo-se os tempos de incubação 3, 96 e 120 horas e incluindo-se mais tempos de incubação entre 6 e 12 horas poderiam ser obtidos dados significativamente diferentes entre si.

A taxa de degradação $(\mathrm{kd})$ encontrada para a MS de $3,34 \% / \mathrm{h}$, desconsiderando os tempos iniciais de 3 e 6 horas e admitindo degradação potencial às 72 horas, é semelhante a obtida por AROEIRA et al. (1993a), de 3,2\%/h, mas difere completamente de $0,2 \% / \mathrm{h}$, conforme VALADARES FILHO et al. (1990), e de 6,0\%/h encontrada por PEREIRA et al. (1996), o que mostra a grande variação entre os valores encontrados para este parâmetro.

Tabela 5 - Taxas de degradação (kd), "lag time" e coeficiente de correlação (r) para MS da cana-de-açúcar Table 5 - Degradation rates $(\mathrm{kd})$, lag time and correlation coefficient $(r)$ for DM of sugar cane

\begin{tabular}{|c|c|c|c|c|}
\hline $\begin{array}{l}\text { Tempo excluído } \\
\text { Excluded time }\end{array}$ & $\begin{array}{l}\text { Degradação potencial }(\mathrm{h}) \\
\text { Potential degradation }(h)\end{array}$ & $\begin{array}{l}\mathrm{kd}(\% / \mathrm{h}) \\
k d(\% / h)\end{array}$ & $\begin{array}{l}\text { "lag time" }(\mathrm{h}) \\
\text { lag time }(h)\end{array}$ & $\begin{array}{l}\mathrm{r} \\
r\end{array}$ \\
\hline Nenhum & 120 & 2,74 & 5,43 & $-0,9920$ \\
\hline $\begin{array}{l}\text { None } \\
3 \text { horas }\end{array}$ & 120 & 2,81 & 7,09 & $-0,9926$ \\
\hline $\begin{array}{l}3 \text { hours } \\
3 \text { e } 6 \text { horas } \\
3 \text { and } 6 \text { hours }\end{array}$ & 120 & 2,90 & 9,10 & $-0,9925$ \\
\hline $\begin{array}{l}\text { Nenhum } \\
\text { None }\end{array}$ & 96 & 3,04 & 4,90 & $-0,9869$ \\
\hline $\begin{array}{l}3 \text { horas } \\
3 \text { hours }\end{array}$ & 96 & 3,15 & 6,55 & $-0,9879$ \\
\hline $\begin{array}{l}3 \text { e } 6 \text { horas } \\
3 \text { and } 6 \text { hours }\end{array}$ & 96 & 3,29 & 8,57 & $-0,9873$ \\
\hline $\begin{array}{l}\text { Nenhum } \\
\text { None }\end{array}$ & 72 & 3,09 & 3,32 & $-0,9919$ \\
\hline $\begin{array}{l}3 \text { horas } \\
3 \text { hours }\end{array}$ & 72 & 3,22 & 4,63 & $-0,9939$ \\
\hline $\begin{array}{l}3 \text { e } 6 \text { horas } \\
3 \text { and } 6 \text { hours }\end{array}$ & 72 & 3,34 & 5,83 & $-0,9931$ \\
\hline
\end{tabular}

Rev. bras. zootec., 30(6S):2126-2133, 2001 
Tabela 6 - Taxas de degradação $(\mathrm{kd})$, "lag time" e coeficiente de correlação $(r)$ para FDN da cana-de-açúcar Table 6 - Degradation rates $(\mathrm{kd})$, lag time and correlation coefficient $(r)$ for NDF of sugar cane

\begin{tabular}{|c|c|c|c|c|}
\hline $\begin{array}{l}\text { Tempo excluído } \\
\text { Excluded time }\end{array}$ & $\begin{array}{l}\text { Degradação potencial }(\mathrm{h}) \\
\text { Potential degradation }(h)\end{array}$ & $\begin{array}{l}\mathrm{kd}(\% / \mathrm{h}) \\
\mathrm{kd}(\% / \mathrm{h})\end{array}$ & $\begin{array}{l}\text { "lag time" (h) } \\
\text { lag time (h) }\end{array}$ & $\begin{array}{l}\mathrm{r} \\
r\end{array}$ \\
\hline $\begin{array}{l}\text { Nenhum } \\
\text { None }\end{array}$ & 120 & 3,83 & 10,19 & $-0,9337$ \\
\hline $\begin{array}{l}3 \text { horas } \\
3 \text { hours }\end{array}$ & 120 & 4,06 & 13,40 & $-0,9352$ \\
\hline $\begin{array}{l}3 \text { e } 6 \text { horas } \\
3 \text { and } 6 \text { hours }\end{array}$ & 120 & 4,37 & 17,59 & $-0,9339$ \\
\hline $\begin{array}{l}\text { Nenhum } \\
\text { None }\end{array}$ & 96 & 2,43 & 5,04 & $-0,9849$ \\
\hline $\begin{array}{l}3 \text { horas } \\
3 \text { hours }\end{array}$ & 96 & 2,55 & 7,32 & $-0,9887$ \\
\hline $\begin{array}{l}3 \text { e } 6 \text { horas } \\
3 \text { and } 6 \text { hours }\end{array}$ & 96 & 2,66 & 9,20 & $-0,9879$ \\
\hline $\begin{array}{l}\text { Nenhum } \\
\text { None }\end{array}$ & 72 & 2,73 & 3,60 & $-0,9843$ \\
\hline $\begin{array}{l}3 \text { horas } \\
3 \text { hours }\end{array}$ & 72 & 2,94 & 5,80 & $-0,9924$ \\
\hline $\begin{array}{l}3 \text { e } 6 \text { horas } \\
3 \text { and } 6 \text { hours }\end{array}$ & 72 & 3,05 & 7,04 & $-0,9913$ \\
\hline
\end{tabular}

As diferenças encontradas entre dietas, para $\mathrm{pH}$, devem-se provavelmente ao fato de os tratamentos U, FU e GU conterem uréia, que sofre a ação dos microorganismos ruminais, liberando amônia, contribuindo para elevação do $\mathrm{pH}$. Para os tempos de coleta, as diferenças encontradas podem ser devido ao horário de alimentação.

As médias dos valores de $\mathrm{pH}$ são comparáveis à encontrada por AROEIRA et al. (1993b), de 6,50, em bovinos alimentados com cana-de-açúcar suplementados com farelo de algodão ou de arroz. Os valores observados foram próximos aos obtidos por PEREIRA et al. (1996), de 6,48 para dieta constituída de cana mais uréia e concentrado.

As médias de concentração de amônia para tratamentos, estão próximas às encontradas na literatu$\mathrm{ra}$, de $166 \mathrm{mg} / \mathrm{L}$ e $236 \mathrm{mg} / \mathrm{L}$ conforme AROEIRA et al. (1993b), $115 \mathrm{mg} / \mathrm{L}$ de acordo com PEREIRA et al. (1996), e de 111,9 mg/L segundo LUDOVICO e MATTOS (1994). Apenas o tratamento UR apresentou valor muito superior, no entanto, deve-se considerar a alta quantidade de uréia fornecida neste tratamento $(0,170 \mathrm{~kg} / \mathrm{an}$. dia $)$.

A análise estatística dos dados de concentração de amônia no fluido ruminal teve alto coeficiente de variação, tanto para tratamentos $(258,43)$, como para tempos de amostragem $(153,28)$, devido a particularidades de dois animais utilizados, uma vez que seus conteúdos ruminais eram atípicos, o que pode ter interferido nas concentrações de amônia no fluido não sendo possível avaliar até que ponto esta variável pode ter influenciado outros parâmetros como pH e degradação.

\section{Conclusões}

As diferentes fontes protéicas avaliadas não influenciaram a degradação da fibra da cana-de-açúcar. Para os tratamentos UR, FS e FU, não eram esperadas diferenças na degradação da fibra, uma vez que foram ajustadas, atendendo o potencial microbiano em proteína degradável. Entretanto, não foram encontradas diferenças para os tratamentos GL e GU, ajustados abaixo do potencial microbiano.

\section{Referências Bibliográficas}

AGRICULTURAL FOOD AND RESEARCH COUNCIL AFRC. 1993. Technical committee on responses to nutrients: energy and protein requirements of ruminants. Wallingford: Commonwealth Agricultural Bureaux International. 159p.

ALCÂNTARA, E., AGUILERA, A., ELLIOT, R. et al. 1989. Fermentation and utilization by lambs of sugar cane harvested fresh and ensiled with and without $\mathrm{NaOH}$. 4. Ruminal kinetics. An. Feed Sci. Technol., 23(4):323-331.

AROEIRA, L.J.M., SILVEIRA, M.I., LIZIERE, R.S. et al. 1993a. Degradabilidade no rúmen e taxa de passagem da canade-açúcar mais uréia, do farelo de algodão e do farelo de arroz em novilhos mestiços europeu x zebu. R. Soc. Bras. Zootec., 22(4):552-564. 
AROEIRA, L.J.M., SILVEIRA, M.I., LIZIERE, R.S. et al. 1993b. Digestibilidade, balanço de nitrogênio e concentração de amônia no rúmen de novilhos mestiços alimentados com cana-de-açúcar e uréia mais farelo de arroz ou de algodão. R. Soc. Bras. Zootec., 22(6):893-901.

AROEIRA, L.J.M., FIGUEIRA, D.G., RODRIGUEZ, N. M. et al. 1993c. Degradabilidade in situ dos nutrientes da cana-deaçúcar e do farelo de algodão em bovinos alimentados com farelo de algodão e cana-de-açúcar adicionada de três níveis de uréia. Arq. Bras. Med. Vet. Zootec., 45(2):221-233.

BELASCO, I.J. 1954. Comparison of urea and protein meals as nitrogen sources for rumen microorganisms : urea utilization and cellulose digestion. J. Anim. Sci., 15(3):496.

BOIN, C., TEDESCHI, L.O. Cana-de-açúcar na alimentação de gado de corte. In: SIMPÓSIO SOBRE NUTRIÇÃO DE BOVINOS, 5., 1993, Piracicaba. Anais... Piracicaba: FEALQ, 1993. p.107-126.

de FARIA, V.P., HUBER, J.T. 1984. Effect of dietary protein and energy levels on rumen fermentation in Holstein steers. J. Anim. Sci., 58(2):453-459.

FRANCO, G.L. Avaliação de parâmetros ruminais de bovinos suplementados a pasto na estação das águas. Jaboticabal, SP: FCAV,1997. 78p. Dissertação (Mestrado em Produção Animal) - Faculdade de Ciências Agrárias e Veterinárias/ Universidade Estadual Paulista,1997.

HOOVER, W.H. 1986. Chemical factors involved in ruminal fiber digestion. J. Dairy Sci., 69(10):2755-2766.

LIMA, M.L.M., MATTOS, W.R.S. Cana-de-açúcar na alimentação de bovinos leiteiros. In: SIMPÓSIO SOBRE NUTRIÇÃO DE BOVINOS, 5., 1993, Piracicaba. Anais...Piracicaba: FEALQ, 1993. p.77-105.

LUDOVICO, A., MATTOS, W.R.S. Parâmetros ruminais de bovinos recebendo dietas à base de cana-de-açúcar (Saccharum officinarum) e diferentes níveis de semente de algodão (Gossypium hirsutum). In: REUNIÃO ANUAL DA SOCIEDADE BRASILEIRA DE ZOOTECNIA, 31., 1994, Maringá. Anais... Maringá, 1994. p.495.
NATIONAL RESEARCH COUNCIL - NRC. 1996. Nutrients requeriments of beef cattle. Washington: National Academy Press. 242p.

PEREIRA, O.G., VALADARES FILHO, S.C., GARCIA, R. et al. 1996. Degradabilidade in vivo e in situ de nutrientes e eficiência de síntese de proteína microbiana, em bovinos, alimentados com cana-de-açúcar sob diferentes formas. R. Soc. Bras. Zootec., 25(4):763-777.

PRESTON.T.R. 1986. Analytical methods for caracterizing feed resources for ruminants. In: PRESTON, T.R. (Ed.) Better utilization of crop residues and by products in animal feeding : research guidelines. 2. A pratical manual for research workers. Rome: FAO. 106p.

PRESTON, T.R. The use of sugar cane and by products for livestock. In: REUNIÃO ANUAL DA SOCIEDADE BRASILEIRA DE ZOOTECNIA, 21., 1984, Belo Horizonte. Anais... Belo Horizonte, 1984. p.101-122.

SILVA, D.J. 1990. Análises de alimentos (métodos químicos e biológicos). Viçosa, MG: UFV. 166p.

SLYTER, L.L., SATTER, L.D., DINIUS, D.A. 1979. Effect of ruminal ammonia concentration on nitrogen utilization by steers. J. Anim. Sci., 48(4):906-912.

UGARTE, J., GAlindo, J., PUJOLS, M. et al. 1994. Substitution of urea by home made protein molasses (HPM) as a supplement for dairy cows fed sugar cane. Effect on milk yield and sugar cane fiber digestibility. Cuban J. Agric. Sci., 28(2):161-165.

VALADARES FILHO, S.C., SILVA, J.F.C., LEÃO, M.I. et al. 1990. Degradabilidade "in situ" da matéria seca e proteína bruta de vários alimentos em vacas em lactação. R. Soc. Bras. Zootec., 19(6):512-522.

Recebido em: 24/10/00

Aceito em: 05/07/01 